\section{УДК $321.01+342.1$}

УРОКИ ЛИМОЛОГИИ И ГЕОПОЛИТИЧЕСКАЯ СТЕРЕОМЕТРИЯ

\author{
Русакова Ольга Фредовна, \\ Институт философии и права \\ УрО РАН, \\ заведующая отделом философии, \\ доктор политических наук, \\ профессор, \\ Екатеринбург, Россия. \\ E-mail: rusakova_mail@mail.ru \\ Русаков Василий Матвеевич, \\ Уральский государственный \\ экономический университет, \\ кафедра философии, \\ доктор философских наук, \\ профессор, \\ Екатеринбург, Россия. \\ E-mail: dipi@nm.ru
}

Аннотация.

В статье анализируется проблема современного понимания и практического воплощения геополитической категории государственных границ с точки зрения перехода от пережитков геополитической планиметрии к современной геополитической стереометрии.

Раздел политической теории «лимология» - учение о границах претерпевает существенные преобразования под влиянием ряда новых факторов: глобализации, научно-технического и технологического прогресса, борьбы против всевластия мирового финансового капитала. Устаревшее «плоскостное» представление о государственных границах, как

«линиях», «стенах» должно быть радикально переосмыслено как границы разнообразных объемов (исторических, социально-политических, юридических, демографических, технологических и т.п.)

и воплощено в диверсифицированной политике.

Ключевые понятия: лимология, геополитика, государственные границы, суверенитет, международное право.
Политическая история человечества полна примеров самого жаркого интереса к всевозможным разграничениям и, особенно, к проведению государственнополитических границ'. Древний Рим дал образец концептуального оформления представлений о границах (limes - лат.), заложив основы учения о государственных границах - лимологии («которая представляет собой поле исследований многих общественных и даже технических наук» [2]). В нашу задачу не входит рассмотрение статуса этой дисциплины в комплексе политических наук. И хотя отечественные исследования в этой области еще не достигли широты и размаха, представленных в современной мировой литературе, науке и практике, тем не менее основополагающие положения сформулированы и имеют глубокий эвристический потенциал².

Необходимо иметь в виду, что если русский термин «граница» используется для обозначения границы любого типа территориального разделения, то английские термины различают разные типы границ, которые и обозначаются разными словами: 1. «border» - граница (имеет наиболее общее значение) обозначает не только разделительную линию, но и прилегающие к ней по обе стороны территории; термин «boundary» - используется, когда пределы сопряженных территорий (более мелких, нежели в случае «border») определены достаточно точно и могут быть нанесены на карту. Кроме того, есть еще один часто встречающийся в border studies термин: «frontier»- граница, рубеж, в смысле укрепленная и охраняемая граница между более крупными территориями, чем в случае с «boundary». Поэтому в зарубежных border studies мы видим исследование и границ, и приграничья и пограничья, а также ближних и дальних рубежей, разграничивающих социокультурные и национально-этнические идентичности, процессы жестких политических дифференциаций.

Современные исследования проблем границ (в самом широком смысле: границ, пограничья и т.п.) развернулись самым широким фронтом - как в предметном плане (прежде всего, как комплексные, междисциплинарные), так и в институциональном (создание исследовательских и учебных центров, объединений, экспертных сооб-

1 Верменич Я. В. Историческая лимология. Проблемы концептуализации [Электронный ресурс] / Я.В. Верменич // URL: http://roii.ru/r/1/40_1 (дата обращения: 05.12.2016).

2 Колосов В. Теоретическая лимологйя: новые подходы [Электронный ресурс] // Международные процессы. 2003. № 3. С. 44-49. URL:: http://www.intertrends.ru/three/004.htm (дата обращения: 05.12.2016). 
ществ, проведение конференций, издание специальных журналов и осуществление различных издательских проектов).

Исследования в области политических границ сегодня разнообразно институционализированы. Д.Ньюман (D.Newman) прямо заявляет о Ренессансе основательного научного интереса к изучению проблем границ: «Исследование границ претерпело возрождение в последнее десятилетие. Это нашло отражено во внушительном списке конференций, семинаров и научных публикаций» [7]. Ему вторит Дж. Хаген: «На рубеже XX века исследования границ, можно с полным основанием утверждать, переживают период возрождения», добавляя, что, по иронии судьбы, этот «ренессанс» совпал с расцветом теорий о наступлении «мира без границ» [5]. Более того, «отражая растущий научный интерес к приграничным исследованиям, был создан ряд научных центров и объединений для распространения информации, поощрения научных исследований и организации конференций по вопросам, касающимся границ»3.

В последние годы возникло множество специализирующихся на изучении данной проблематики ассоциаций, организаций и объединений: «Ассоциация исследования пограничья» ${ }^{4}$, «Центр изучения международных границ» ${ }^{5}$, «Африканская сеть приграничных исследований(ABORNE)»6, «История приграничья»", «Ассоциация Европейских приграничных регионов (АЕПР)», «IBRU: Centre for Borders Research» (Даремского университета) ${ }^{8}$, «Ассоциация региональных исследований» (RSA - Regional Studies Association $)^{9}$ и многие другие. Они проводят конференции, издают журналы, объединяют и координируют усилия специалистов в области изучения границ, пограничья и т.п.

Выпускается значительное количество периодических изданий, ведущих интенсивные исследования проблем границ, по- граничья и приграничья и т.д. - такие, как Geopolitics ${ }^{10}$; Journal of Borderlands Studies ${ }^{11}$, Space and Polity ${ }^{12}$ Political Geography ${ }^{13} n$ мн.др.

Крупнейший справочный ресурс издательства Оксфордского университета: Oxford Bibliographies подготовил солидный библиографический указатель литературы по проблемам изучения границ и приграничья (Дж.Хаген, Университет Маршала (Joshua Hagen, Marshall University, Западная Вирджиния, (ША), в котором перечислено большое количество источников практически по всем основным и актуальным разделам нового комплексного изучения проблем границ и пограничья (классические работы, журналы, изучение морских границ и границ современного «мира без границ», исторической перспективы границ и т.п. $)^{14}$

В то же время Д. Ньюман справедливо обращает внимание на то, что «...исследование границ вышло за ограниченные рамки политической географии, пересекая дисциплинарные границы, чтобы включить социологов, политологов, историков, юристов-международников и специалистов в области международных отношений» [7].

Прилив исследовательского внимания к проблемам границ (в самом широком смысле этого термина) обусловлен целым рядом причин.

Во-первых, глобализация и вызванные ею процессы интенсивного перемещения через государственные границы труда и капитала - финансовых, человеческих, материально-вещественных и информационных ресурсов вызвали к жизни либеральную концепцию формирования «мира без границ», в котором государственные границы становятся все более условными, размытыми, прозрачными и проницаемыми. Складывание международных финансовых центров, часто куда более могуществен-

3 Первую Всемирную конференцию ABS организовала в Joensuu (Финляндия) - Санкт-Петербург (Россия) в июне 2014, вторая планируется в июле 2018, в Вене и Будапеште.

${ }^{4}$ Association for Borderlands Studies (ABS) (http://absborderlands.org ) - которая, кстати, выступила с инициативой предложить Генеральной Ассамблее Организации Объединенных Наций объявить 7 июня Международным днем интеграции через национальные границы.

${ }_{5}$ Centre for International Borders Research (http://www.qub.ac.uk/research-centres/)

${ }^{6}$ African Borderlands Research Network (ABORNE) http://www.aborne.org.

${ }^{7}$ Borderlands History (https://borderlandshistory.org).

8 IBRU: Centre for Borders Research (https://www.dur.ac.uk/ibru/)

${ }_{9}$ RSA (http://www.regionalstudies.org).

${ }^{10} \mathrm{http}: / /$ www.tandfonline.com/toc/fgeo20/current.

${ }^{11}$ http://absborderlands.org/journal-of-borderlands-studies/

${ }^{12}$ http://www.tandfonline.com/toc/cspp20/current.

${ }^{13}$ http://www.journals.elsevier.com/political-geography/

${ }^{14}$ Hagen Joshua. Borders and Boundaries

http://www.oxfordbibliographies.com/view/document/obo-9780199874002/obo-9780199874002-0056.xml 
ных, чем национальные государства с их бюджетами резко обесценивает границы, превращает их почти что в досадный архаизм, камнем лежащий на путях свободного перемещения капитала и рабочей силы.

Во-вторых, информационное общество формирует глобальные информационные сети и такие же потоки информации, не признающие государственных границ (так что часто государства в страхе пытаются возводить преграды, которые также рассматриваются как проявление отсталости или даже реакционности) - ставят вопрос о роли государственных границ в современном мире.

В-третьих, экологические проблемы получили статус глобальных: антропогенное воздействие на окружающую среду наглядно демонстрирует острейшую необходимость трансграничного сотрудничества государств.

В-четвертых, проблема защиты прав человека также не только выводит политику за пределы национальных границ, но весьма остро ставит вопрос о том, что государственные границы могут, и используются, - как орудие и средство нарушения прав человека.

В-пятых, человечество приступает к интенсивному освоению качественно новых для него областей существования: арктический шельф ${ }^{15}$, мировой океан и его дно; арктическое и антарктическое пространство, ближнее и дальнее космическое пространство $^{16}$, небесные тела. Эти области имеют принципиально трансграничный характер, императивно предписывающий вовлеченным странам решать проблемы международного сотрудничества, основанного на иных принципах, нежели традиционное проведение разграничительных линий.

Наконец, нельзя забывать - и в современной литературе постоянно обращается на это внимание: существует транснациональный криминал, резко обостряющий проблемы законности и безопасности: международная организованная преступность (наркотрафик, работорговля, торговля оружием, терроризм) использует трансграничные связи и перемещения как свой значительный ресурс, а государственные границы часто рассматривают как спасительное укрытие ${ }^{17}$.

Однако картина современного состояния исследовательского интереса к комплексной проблематике государственных границ была бы явно односторонней, если бы мы обошли вниманием другой ряд причин, которые, напротив, вызвали к жизни многообразные проявления политики активного отстаивания необходимости государственных границ вплоть до архаического “стеностроительства» ${ }^{18}$.

Во-первых, транснациональный финансовый капитал стал главным выгодоприобретателем международных интеграционных процессов и даже в объединенной Европе, которая позиционировала себя как пример и образец решительного снижения роли государственных границ («евроинтеграция») как устранения барьеров на путях построения «общеевропейского дома» - все больший вес набирают центробежные тенденции, растет «евроскептицизм». Сегодня все более трудно скрыть силу и корыстный интерес «невидимых правительств» в форме транснациональных финансовых корпораций, которым нет дела до национальных интересов (в сфере благосостояния, здравоохранения, образования культуры, защиты окружающей среды и прав человека), которые обязаны защищать национальные государства в границах своей суверенной территории. Что происходит с суверенитетом и «свободным перемещением труда и капитала» в случае подчинения их транснациональным корпорациям - современность дает нам множество примеров.

Во-вторых, транснациональный финансовый капитал, окончательно порвав-

15 Конвенция о континентальном шельфе (1958); О континентальном шельфе Российской Федерации. Федеральный закон от 30 ноября 1995 г.; О порядке утверждения перечней географических координат точек, определяющих линии внешних границ континентального шельфа Российской Федерации. Постановление Правительства РФ от 16 июня 1997 г.

16 Соглашение о спасании космонавтов, возвращении космонавтов и возвращении объектов, запущенных в космическое пространство, 1968 г

17 См. литературу в разделе «Security, Conflict, and Crime» в: Hagen Joshua. Borders and Boundaries http://www.oxfordbibliographies.com/view/document/obo-9780199874002/obo-9780199874002-0056.xml

18 Пошкявичуте Ю. Политика возведения стен: аргументы властей и реальные последствия [Электронный ресурс] // URL:http://www.geopolitika.It/?a=71 (дата обращения: 05.12.2016); Австрия решила построить антимигрантскую стену [Электронный ресурс]. /http://lenta.ru/news/2015/10/28/austria_border_fence/ (дата обращения: 05.12.2016); Армия Македонии начала строить металлический забор на границе с Грецией [Электронный ресурc] URL: //http://www.kommersant.ru/Doc/2865322(дата обращения: 05.12.2016); Государства, отгородившиеся стеной от своих соседей [Электронный ресурс] URL://http://diletant.media/articles/25896545/ (дата обращения: 05.12.2016) 
ший с «реальным» сектором экономики (где производятся потребительные стоимости и воспроизводится человек), рассматривает все исторически данные различия - культуры, языка, пола, возраста, истории и пр. - как препятствия на пути его высшей цели: самовозрастания его меновой стоимости. Подчинение финансовым «пузырям» спекулятивного финансового капитала всех сторон жизни человека (образование, наука и культура «должны обслуживать» бизнес, здравоохранение и вся социальная сфера - вообще рассматриваются как "непрофильный актив», подлежащий безусловной «оптимизации») оборачивается настоящей антропологической катастрофой.

В таком контексте происходит интенсификация исследований в области лимологии. Авторы, практически, единодушно сходятся в том, что для успеха необходимо обновление исследовательского инструментария, поскольку, как уже выше было замечено, проблема приобрела статус междисциплинарной. И здесь необходимо отметить несколько важных аспектов.

Прежнее представление о государствен ных границах сегодня неизбежно претерпевает существенные изменения, которые идут в русле отхода от «плоскостной» концепции границ («геополитическая планиметрия») к объемному представлению («геополитической стереометрии»). Как известно, уже П. Сорокин различал географическое («геометрическое») и социальное пространство: «социальное пространство есть нечто совершенно отличное от геометрического пространства», - говорил он.

В свете комплексного междисциплинарного видения проблемы современного определения границы политическая практика неизбежно потребовала дополнения и развития смысла «граница», указанного в формулировке закона РФ: 1. «Государственная граница Российской Федерации» гласит: «Государственная граница Российской Федерации (далее - Государственная граница) есть линия и проходящая по этой линии вертикальная поверхность (курсив наш - авт.), определяющие пределы государственной территории (суши, вод, недр и воздушного пространства) Российской Федерации, то есть пространственный предел действия государственного суверенитета Российской Федерации» ${ }^{19}$. Поэтому появляется такие документы, как Указ Президента РФ «Основы пограничной политики Российской Федерации». ${ }^{20}$

Эта тенденция хорошо видна в формулировках современных документов: от линии на местности - к вертикальной плоскости; от единственной линии госграницы - к границам привилегированных экономических зон; далее - к границам, разделяющим воздушное и космическое пространство; от линий на поверхности мирового океана - к разграничениям шельфа, дна мирового океана.

Вопрос о границах территории особенно актуализируется, как только мы переходим к относительно новым феноменам, например, к границам шельфа. Здесь неизбежно складывается представление о том, что правовое понятие континентального шельфа не совпадает с его геоморфологической характеристикой, что правовое определение шельфа существенно связано с техническими аспектамиㄹ․ Еще более очевидна эта проблема в определении границы между воздушным пространством и космическим.

Но неразрешенность теоретическая выливается в неурегулированность внутренних и международных политических, экономических, социальных, демографических и т.п. процессов, что оборачивается политическими напряжениями и конфликтами. Причем упования на автоматическую «всеразрешающую» способность международного права, как показывает опыт, малоосновательны.

Кроме того, практическая проблема реального обеспечения суверенитета территории в ее определенных границах обнаруживает себя со всей остротой, потому что реальная политическая, экономическая, социальная и духовно-практическая жизнедеятельность людей, населяющих приграничные территории, вполне может приходить в противоречие с «линиями» и «границами». Разграничительные линии могут весьма болезненно разрезать исторические связи, многовековой уклад, экономические отношения, повседневную жизнь людей, часто не просто обременяя ее всевозможными тяготами, но и прямо неся бедствия

19 О Государственной границе Российской Федерации. Закон РФ от 1 апреля 1993 г. N 4730 -I [Электронный ресурc] URL:http://base.garant.ru/10103372/\#ixzz4Ru15Xhbl (дата обращения: 05.12.2016).

20 Основы пограничной политики РФ. Указ Президента РФ от 9 октября 1996 г.

21 В Конвенции о континентальном шельфе 1958 г. внешняя граница континентального шельфа не была четко установлена, так как ее пределы ставились в зависимость от технических возможностей каждого государства. 
и страдания. Линии, стены, границы часто скоропалительно и крайне упрощенно рассматриваются как «простое» и эффективное решение застарелых социально-экономических и политических проблем - политической вражды, вынужденной миграции и беженства, социально-экономического несправедливого неравенства.

Однако, как замечает В. Колосов: «Географическое изучение границ нуждалось в свежих теоретических подходах. Стало ясно, что границы ныне нельзя изучать только на уровне страны. С одной стороны, все более заметную роль в мире играют наднациональные организации, а с другой, в ответ на интернационализацию хозяйства и унификацию культуры пробуждается региональное самосознание» [2]. Сегодня все более общепризнанным становится взгляд, согласно которому «наиболее важным является понимание границ как процесса... Этот акцент на процессе выделяет границы в качестве активных сил и ресурсов в международных и внутренних политических, социальных и экономических отношений... границы будут демонстрировать большую изменчивость и функционирование в чрезвычайных ситуациях в будущем, что делает их изучение еще более важным для понимания их по более широкому кругу вопросов» [5]. Исследование границ, приграничья показывают, что «проблема заключается в восприятии границ как пассивных линий на карте, а не выявление их интегральных сил в экономических, социальных, политических и экологических процесса, которые формируют нашу жизнь. Вопрос о границах включает в себя такие соображения, как транснациональных сообществ, угрозы безопасности со стороны террористических групп, регулирования миграции, защиты прав коренных народов, правового статуса моря и космического пространства, охраны окружающей среды» $[5 ; 8]$.

Разумеется, сегодня, после того, развеялись наивные представления о «мире без границ», становится ясно, что «границы являются неотъемлемыми компонентами человеческой деятельности и организации». Ограничение пространства всегда было, и наверное будет всегда, особенностью человеческого опыта» [8]. Но вопрос в том, как понимается и практически реализуется идея всевозможных «линий» и «плоскостей».

И если государство (например, российское) продолжает рассматривать свои границы как «линии» или «вертикальные плоскости», продолжающие эти линии в воздуш- ном, морском, космическом пространствах, которые надо зафиксировать и охранять, то такая политика явно устарела, и сама граница, и ее обеспечение (нерушимости, безопасности), и ее использование в интересах страны и народа - сегодня приобретают существенно объемный характер.

Во-первых, приходится иметь дело с множеством исторических реалий (исторических событий, архивных документов, договоров, письменных источников), игнорировать которые - значит, создавать прецеденты и исключения, которые превращаются в правила. Дело в том, что исторические аспекты границ не есть нечто "сданное в архив», всего лишь давно прошедшее. Исторические события далекого прошлого остаются актуальными реалиями. Стоит только признать права Японии хотя бы на некую «островную гряду», тотчас мы столкнемся с множеством крайне опасных последствий фактического пересмотра итогов Второй мировой войны, а далее - вполне вероятно, с созданием военно-морской базы США, поскольку полнота суверенитета Японии над своей территорией весьма проблематична (что уже было однажды доказано судьбой договора СССР-Япония 1956 г.).

Во-вторых, в повестку дня для следующего поколения пограничных исследований следует ввести новый раздел: «границы должны рассматриваться на предмет их способности составлять мосты и точки соприкосновения, в противовес тому, как они традиционно представляются барьерами для передвижения и коммуникации» [7; 8]. Не случайно, значительное развитие получили исследования в области так называемой «парадипломатии», т.е. разнообразного приграничного сотрудничества, в котором видят одну из самых перспективных тенденций развития международных отношений [6].

В-третьих, это постоянная полити ческая международно-правовая работа. Границы государств подобны мембранам живого организма, которые должны выполнять двоякую функцию: обеспечивать целостность организма и его постоянный обмен с внешним миром (политический, экономический, культурный, информационный, юридический и т.п.). Например, подкомиссия ООН признала акваторию Охотского моря внутренним морем Российской Федерации (2013 г.). Это означает, что стране добавилось 52 тысячи кв. км территории, и какой: одной из самых богатых морскими природными ресурсами в мире. Открой Россия свободный доступ к этой акватории всем, кто хочет, - и мы 
лишимся уникальных богатств. Их и сегодня Российская Федерация не в состоянии полностью поставить под свой суверенный контроль (речь идет не только об эффективной борьбе с незаконным промыслом, но и о крайне неэффективной организации системы переработки, таможенной службы, охраны природы и т.п.).

Нельзя забывать, что обширные территории Сибири от р. Лены до Чукотки (пресловутый «Леналенд»), арктические территории - провокационно рассматриваются западными (прежде всего, американскими) стратегами как пояс «бросовых» земель, которыми Россия якобы не в состоянии эффективно распорядиться и которые неплохо было бы поставить под международный контроль [1]. Сейчас идет интенсивная работа по обеспечению права распространения российского суверенитета на обширные арктические территории, потенциально богатые углеводородами, что требует огромных финансовых, материальных (технических) и людских ресурсов. В "Стратегии национальной безопасности США - 2015» и в выступлениях президента США 22 было чётко указано: суть национальной безопасности страны состоит в обеспечении американской исключительности, глобального доминирования и всемирного лидерства, поэтому должно быть очевидным, что “санкционная» политика вовсе не есть сиюминутная раздражительность великой державы (вспомним, историю знаменитой неотменимой «поправки Джексона-Вэника»).

В конечном счете, линии, дуги, оси, стены, плоскости, границы и прочее суть политико-идеологические феномены, идеальная сущность которых лишь подчеркивает, что корень их существования заключается глубоко в теле политики государства, хотя и несводимой к различным материально-вещественным выражениям, придаткам и орудиям, но необходимо реализующейся через них. Как верно замечено, «граница - это не только линия на географической карте, край, рубеж некоего географического пространства, территории. Это некий край пространства власти, т. е. территории, стратифицированной при помощи властных технологий [3], зона соприкосновения, пересечения, наложения различных, часто разнотипных пространств и структур власти» [3, с. 141]. А. Динер и Д. Хаген в этом же смысле подчеркивают, что «в то время как государственные границы, как правило, рассматриваются в качестве довольно резких разделительных линий, последние исследования подчеркнули суть границ и пограничья в качестве объектов культурного взаимодействия, обмена и, возможно, некой гибридности» [8]. В стремлении уйти от «линеарности» понимания границы некоторые авторы прибегают к метафоре «позвоночника», приводя исторические примеры: «вместо того, чтобы думать о вале Адриана, как о заборе, было бы точнее рассматривать его как позвоночник, вокруг которого Римский контроль над Северной Британией был установлен и стабилизирован» [8].

Границы лишь тогда обретают «плотность» (и значимость), когда внешнее воздействие испытывает сопротивление, а не пустоту: «пространство власти» существует как властно-распорядительное, физическое, технологическое, сопротивление самоидентификации населения - как приграничья, так и центра. А это, как мы видим, связано с множеством фундаментальных факторов. Компрадорская политика сдачи страны в аренду или субаренду однозначно не создает ощутимого пространства (объема) власти, сопротивляющейся унификации самоидентификации (дети «элиты» честно проговаривают то, что у их родителей на уме: в своих безыскусных интернет-исповедях они признаются, что в «Рашке» однозначно плохо, здесь их ничто не держит). 3. Бжезинский, советник по национальной безопасности в администрации Картера, а в период президентства Клинтона автор концепции расширения НАТО на Восток, как-то сказал: «Я не вижу ни одного случая, в котором Россия могла бы прибегнуть к своему ядерному потенциалу, пока в американских банках лежит \$500 млрд, принадлежащих российской элите. Вы ещё разберитесь, чья это элита - ваша или уже наша» ${ }^{23}$.

22 Выдержки из выступления президента США Барака Обамы 13.02.2015 г: «Успешная стратегия обеспечения безопасности американского народа и продвижения интересов нашей национальной безопасности должна начинаться с одной неоспоримой истины - Америка должна быть лидером... Мы демонстрируем за рубежом, что готовы действовать в одностороннем порядке, когда возникают угрозы нашим коренным интересам» // https://electives.hse.ru/data/2015/09/14/1089015615/Майнор\%20БПД\%20тема\%204.pdf.

${ }_{23}$ Катасонов: «Россия - всего лишь кормушка для наших офшорных олигархов-агентов влияния Запада». http://kolokolrussia.ru/novosti/katasonov-rossiya---vsego-lish-kormushka-dlya-nashih-ofshornholigarhovagentov-vliyaniya-zapada\#hcq=RhDQQ7q Катасонов В.: «Надо понимать, что офшоризация российской экономики - это не столько финансовые потери, сколько, в первую очередь, потеря политического суверенитета», - отметил Катасонов в интервью День ТВ». 
1. Бжезинский, 3. Великая шахматная доска: господство Америки и его геостратегические императивы [Текст] / 3. Бжезинский / пер. с англ. О.Ю. Уральской. М.: Международные отношения, 1998. 255 c.

2. Колосов, В.А. Теоретическая лимология [Текст] / В. Колосов // Мировая политика: теория, методология, прикладной анализ / под ред. А.А. Кокошина и А.Д. Богатурова. М.: УРСС, 2005. $428 \mathrm{C}$.

3. Королев, С.А. Края пространства [Электронный ресурс] / С.А. Королев. URL: http://citeseerx. ist.psu.edu/viewdoc/download?doi=10.1.1.98.3259\&r ep=rep1\&type=pdf (дата обращения: 18.12.2016).

4. Кузьмин, В.М. Политическая лимология в системе наук о границах: Исследование приграничных регионов [Текст] / В.М. Кузьмин // Вестник РГУ им. И. Канта. 2008. Вып. 6. Гуманитарные науки. С. 65-71.

5. Hagen Joshua. Borders and Boundaries. [Электронный ресурс]. URL: http://www. oxfordbibliographies.com/view/document/obo9780199874002/obo-9780199874002-0056.xml (дата обращения: 18.12.2016).

6. Kuznetsov A. Theory and Practice of Paradiplomacy: Subnational Governments in International Affairs [Text] / eds. Routledge, 2014. 174 pp.

7. Newman, David. The Lines That Continue to Separate Us: Borders in Our 'Borderless' World [Text]. Progress in Human Geography 30.2 (2006). 143-161 рр. В этой работе (примечательно озаглавленной «Линии, которые продолжают разделять нас: границы в нашем «Мире без границ»). Д. Ньюман приводит 315 источников по указанной проблеме (за 1916-2005 гг.).

8. Diener, Alexander C. and Hagen Joshua. Borderlines and Borderlands. Political oddities at the edge of the nation-state. [Text]/ Edited by Alexander C. Diener and Joshua Hagen. Lanham, MD: Rowman \& Littlefield, 2010. 283 pp.

\section{References}

1. Bzhezinskij Z. (1997) The grand chessboard: American primacy and its geostrategic imperatives New York, Basic books, October [in Eng].

2. Kolosov V.A. (2005) Teoreticheskaja limologija / Mirovaja politika: teorija, metodologija, prikladnoj analiz. Pod red. A.A.Kokoshina i A.D. Bogaturova. Moscow, URSS, 428 p. [in Rus].

3. Korolev S.A. Kraja prostranstva, available at: http://citeseerx.ist.psu.edu/viewdoc/download ?doi=10.1.1.98.3259\&rep=rep1\&type $=p d f$ (accessed 18.12.2016) [in Rus].

4. Kuz'min V.M. (2008) Vestnik RGU im. I. Kanta, vyp. 6, Gumanitarnye nauki, pp. 65-71 [in Rus].

5. Hagen Joshua. Borders and Boundaries, available at: http://www.oxfordbibliographies. com/view/document/obo- 9780199874002 /obo9780199874002-0056.xml (accessed 18.12.2016) [in Eng].

6. Kuznetsov A. (2014) Theory and Practice of Paradiplomacy: Subnational Governments in International Affairs / eds. Routledge, 174 p. [in Eng].

7. Newman David (2006). Progress in Human Geography, 30.2, pp. 143-161 [in Eng].

8. Diener Alexander C. and Hagen Joshua (2010). Borderlines and Borderlands. Political oddities at the edge of the nation-state. Lanham, MD, Rowman \& Littlefield, 283 p. [in Eng].
UDC $321.01+342.1$

\section{LESSONS OF LIMOLOGY AND GEOPOLITICAL STEREOMETRY}

\section{Rusakova Olga Fredovna,}

Institute of Philosophy and Law of the Ural Department of Russian Academy of Sciences,

Head of the Department of Philosophy, Doctor of Political Sciences, Professor, Yekaterinburg, Russia.

E-mail: rusakova_mail@mail.ru

\section{Rusakov Vasiliy Matveevich,}

Ural State University of Economics, Department Chair of Philosophy, Doctor of Philosophy, Professor, Yekaterinburg, Russia.

E-mail:dipi@nm.ru

\section{Annotation}

The article analyzes the problem of present-day understanding and practical implementation of geopolitical category of state borders from the viewpoint of transition from the vestiges of geopolitical plane geometry to the present-day geopolitical stereometry. The branch of political theory "limology" is a theory of borders which experiences essential transformations under the influence of new factors: globalization, scientific and technical and technological progress, fighting against absolute power of the world financial capital.

The traditional "plane" concept of state borders as of "lines", "walls" must be completely reconsidered as borders of various volumes (historical, social and political, judicial, demographic, technological, etc.) and implemented into diversity politics.

Key concepts:

limology, geopolitics, state borders, sovereignty, international law. 